\title{
PERANCANGAN ALAT PRESS BIJI MELINJO DENGAN MENGGUNAKAN METODE QUALITY FUNCTION DEPLOYMENT (QFD)
}

\author{
Muhammad Zakaria $^{1^{*}}$, Mustafa Kamal ${ }^{1}$ dan Syukriah ${ }^{1}$ \\ ${ }^{1} J u r u s a n$ Teknik Industri Fakultas Teknik Universitas Malikussaleh, Lhokseumawe, Indonesia \\ *Corresponding Author:irmuhammad@unimal.ac.id
}

\begin{abstract}
Abstrak - Quality Function Deployment (QFD) merupakan suatu metodologi yang digunakan oleh perusahaan untuk mengantisipasi dan menentukan prioritas kebutuhan dan keinginan konsumen, serta menggabungkan kebutuhan dan keinginan konsumen tersebut dalam produk dan jasa yang disediakan bagikonsumen. Berdasarkan definisinya, QFD merupakan praktek untuk merancang suatu proses sebagai tanggapan terhadap kebutuhan pelanggan. Penerapan metodologi QFD dalam proses perancangan produk diawali dengan pembentukan matrik atau sering disebut sebagai House Of Quality(Rumah Kualitas) yang mampu menggambarkan tingkat kualitas produk/jasa yangdihasilkan perusahaan saat ini dan tingkat kualitas yang sebenarnya diinginkan pelanggan, yang meliputi karakteristik keinginan konsumen, karakteristik kualitas yang diberikan kompetitor.Tujuan yang ingin dicapai dalam penelitian ini adalah: menentukan atribut-atribut sebagai landasan upaya perancangan alat press biji melinjo, mengetahui pendapat konsumen tentang alat press biji melinjo. Penelitian dilakukan dengan menggunakan metode Quality Function Deployment(QFD).Hasil yang dicapai adalah: terdapat 9 (sembilan) atribut yang dianggap penting oleh konsumen dan dapat digunakan untuk mengukur kualitas alat press biji melinjo, yaitu: bentuk gagang panjang, bentuk pegangan oval, bentuk tempat tekan bulat, panjang gagang $40 \mathrm{~cm}$, tinggi alat $50 \mathrm{~cm}$, warna hitam, bahan rangka besi, bahan pegangan karet, fungsi utama untuk pembuatan emping. Tampilan produk sudah sangat memuaskan, Prioritas upaya yang dilakukan perusahaan dalam upaya peningkatan kualitas alat press biji melinjo bedasarkan House of Quality adalah: Menjamin bahwa alat press tersebut benar-benar dirancang semenarik mungkin.
\end{abstract}

Kata Kunci: Quality Function Deployment, voice of the customer.

\section{Pendahuluan}

Melinjo adalah tanaman biji-bijian yang telah banyak dimanfaatkan oleh masyarakat. Daun muda biasanya dimanfaatkan sebagai bahan sayuran, sedangkan biji dalamnya digunakan sebagai bahan dasar pembuatan emping. Salah satu produk pertanian di kabupaten pidie adalah melinjo. Melinjo selama ini di olah oleh masyarakat untuk di jadikan emping. Emping melinjo sangat disukai oleh masyarakat dan memiliki nilai ekonomi yang relatif tinggi dengan harga mencapai Rp. 50.000/kg sampai Rp. $70.000 / \mathrm{kg}$. Tingginya harga emping ini mendorong petani di kabupaten pidie membudidayakan melinjo dan meng-olahnya menjadi emping. Pengolahan biji melinjo menjadi emping selama ini dilakukan dengan cara memukul 2-3 kali gerakan dengan menggunakan palu.
Pembuatan emping melinjo sebagai mana tersebut di atas di nilai kurang ekonomi karena membutuhkan waktu yang lama. Untuk proses pembuatan emping 1 bambu melinjo bisa menghabiskan waktu sekitar 2 jam. Pengrajin di desa tersebut mengatakan bahwa hanya bekerja selama 7 jam dalam sehari dengan menghabiskan biji melinjo 3,5 bambu. Kalau dalam sebulan pengrajin hanya bekerja cuma 25 hari jadi meng-habiskan biji melinjo 87,5 bambu dengan ongkos pembuatan emping Rp. $15.000 /$ bambu.

Jelas terlihat bahwa proses pemipihan emping melinjo meng-gunakan palu produktivitasnya sangat rendah. Karena itu, dibutuhkan alat yang memudahkan pemipihan emping melinjo.Dalam proses perancangan alat tersebut pengrajin emping melinjo dilibatkan agar dapat dirancang produk sesuai dengan keinginan dan spesifikasi kebutuhan pengrajin emping melinjo. Untuk 
merancang produk tersebut metode yang digunakan adalah Quality Function Deployment (QFD), yang merupakan sebuah metode peran-cangan langsung melibatkan konsumen (pengrajin emping) dikaitkan dengan aspek kualitas. Keterlibatan konsumen diperlukan untuk mengetahui yang dirasakan, diinginkan, dibutuhkan, dan kesan konsumen terhadap suatu produk sehingga hal tersebut dapat mempermudah proses perancangan produk. Quality Function Deploy-ment (QFD) adalah suatu metodologi untuk menterjemahkan kebutuhan dan keinginan konsumen ke dalam suatu rancangan produk yang memiliki persyaratan teknik dan karakteristik kualitas tertentu. Berdasarkan latar belakang diatas penelitian ini bertujuan untuk merancang sebuah alat pemipihan emping melinjo dengan judul "Perancangan Alat Pemipih Biji Melinjo untuk pembuatan emping Menggunakan Metode Quality Function Deployment (QFD)".

Adapun tujuan yang ingin dicapai dalam melakukan penelitian ini adalah sebagai berikut:

a. Untuk mengetahui atribut yang dibutuhkan oleh konsumen terhadap perancangan alat press biji melinjo.

b. Untuk dapat memahami dan mengaplikasikan metode QFD dalam perencanaan pembuatan alat press biji melinjo agar dapat menghasilkan alat press biji melinjo yang sesuai dengan kebutuhan konsumen.

c. Untuk mengetahui produk alat press biji melinjo yang sesuai dangan hasil perancangan alat tersebut

\section{Landasan Teori}

Tanaman melinjo (Gnetum gneman.L.), termasuk jenis tanaman yang telah dikenal sejak ratusan tahun silam. Namun meski begitu, tanaman ini sampai sekarang belum dikembang-kan secara serius, baik oleh masyarakat maupun pemerintah. Padahal, tanaman melinjo saat ini telah menjadi komoditas ekspor, baik dalam bentuk segar maupun olahan. Sampai saat ini, melinjo ditanam masyarakat hanya dijadikan tanaman peneduh di halaman. Keistimewaan tanaman ini sebenarnya, selain memberikan keuntungan seumur hidup bagi si penanamnya, juga bisa menjadi tanaman warisan untuk anak cucu. Sebab tanaman ini, usianya bisa sampai ratusan tahun.

Secara umum, tanaman melinjo dapat berbuah dua kali dalam setahun. Bahkan bila tumbuh pada tanah yang cocok, bisa panen sampai tiga kali. Sedangkan usia panen perdana, bila tanaman dipelihara dengan baik dapat berlangsung cepat pada usia dua sampai tiga tahun. (Noegraha, A. 2010).

\section{Quality Function Deployment (QFD)}

Quality Quality

Function

Deployment (QFD) diperkenalkan oleh Yoji Akao, Professor of Management Engineering dari Tamagawa University yang dikembangkan dari praktek dan pengalaman industri-industri di Jepang. Pertama kali dikembangkan pada tahun 1972 oleh perusahaan Mitsubishi di Kobe Shipyard, dan diadopsi oleh Toyota pada tahun 1978, dan tahun-tahun selanjutnya dikembangkan oleh perusahaan lainnya.

Fokus utama dari QFD ini yaitu melibatkan pelanggan pada proses pengembangan produk sedini mungkin. Filosofi yang mendasarinya adalah bahwa pelanggan tidak akan puas dengan suatu produk meskipun suatu produk yang dihasilkan sempurna, seperti yang kemarin dikatakan diposting sebelumnya mengenai kualitas bahwa produk yang superior atau sempurna belum tentu di butuhkan oleh konsumen.

QFD merupakan suatu metodologi yang digunakan oleh perusahaan untuk mengantisipasi dan menentukan prioritas kebutuhan dan keinginan konsumen, serta meng-gabungkan kebutuhan dan keinginan konsumen tersebut dalam produk dan jasa yang disediakan bagi konsumen.

Metodologi QFD dalam proses perancangan dan pengembangan produk terdapat empat jenis tahapan yang disebut oleh Cohen (1995) sebagai empat fase model QFD, yaitu:

a. Tahap Perencanaan Produk (House of Quality). Tahapan ini menjelaskan tentang customer needs, technical requirements, corelationship, relationship, custo-mer competitive evaluation, competitive technical assement, dan targets.

b. Tahap Perencanaan Komponen (Part Deployment). Tahap ini merupakan faktor teknis yang critical terhadap pengembangan produk.

c. Tahap Perencanaan Proses (Proces Deployment). Tahap ini merupakan matriks proses pembuatan pengembangan suatu produk.

d. Tahap Perencanaan Produksi (Production Planning). Tahap ini memaparkan tindakan yang perlu diambil didalam perbaikan kualitas produk.

Manfaat QFD bagi perusahaan yang berusaha meningkatkan daya saingnya melalui perbaikan kualitas dan produktifitasnya secara ber-kesinambungan adalah sebagai berikut: (Karuniawati, 2009)

a. Fokus pada pelanggan.

Organisasi TQM merupakan organisasi yang berfokus pada pelang-gan. QFD memerlukan pengumpulan masukkan dan umpan balik dari pelanggan.

b. Efisiensi waktu.

QFD dapat mengurangi waktu pengembangan produk karena mem-fokuskan pada persyaratan pelanggan yang spesifik dan telah diidentifikasi-kan dengan jelas. 
c. Orientasi kerja sama tim (Team work Oriented).

QFD merupakan pendekatan kerjasama tim. Semua keputusan dalam proses didasarkan konsensus dan dicapai melalui diskusi mendalam dan brainstorming.

d. Orientasi pada dokumentasi.

Salah satu produk yang dihasilkan dari proses QFD adalah dokumen komprehensif mengenai semua data yang berhubungan dengan segala proses yang ada dan perbandingannya dengan persyaratan pelanggan.

\section{Metodologi Penelitian}

Untuk mendapatkan berbagai macam data yang dibutuhkan dalam penelitian ini, peneliti menggunakan beberapa teknik pengumpulan data, yaitu:

a. Observasi

Observasi yaitu melakukan penga-matan secara langsung dilapangan. Dalam penelitian ini pengamatan dilakukan pada para pekerja pembuatan emping melinjo.

b. Wawancara

Wawancara yaitu melakukan tanya jawab dengan pihak yang terkait, yaitu para pekerja pembuat emping melinjo tentang keluhan-keluhan dirasakan.

c. Kuesioner

Kuesioner yaitu daftar pertanyaan yang diberikan kepada responden sesuai dengan kebutuhan. Dalam penelitian ini data yang diambil adalah data tingkat kepentingan dan kepuasan konsumen.

Adapun teknik pengolahan data yang digunakan dalam penelitian ini adalah sebagai berikut:

a. Merekap data hasil penelitian

Hasil data yang diperoleh berupa data kepentingan dan kepuasan pengrajin emping melinjo.

b. Pengujian Uji Validitas dan Reliabilitas

Pengujian uji validitas dan pengujian reliabilitas ini dilakukan dengan menggunakan aplikasi spss.

c. Penetapan Tingkat Kepentingan Konsumen

Penentuan tingkat kepentingan konsumen digunakan untuk menge-tahui sejauh mana konsumen memberikan penilaian dari kebutuhan konsumen yang ada. Penilaian tingkat kepentingan terhadap atribut kebutuhan konsumen diperoleh berdasarkan nilai modus pada kuesioner tertutup. Nilai modus yang menjadi tingkat kepen-tingan diperoleh berdasarkan frekuensi jawaban responden yang paling banyak pada setiap atribut.

d. Pengukuran Tingkat Kepuasan Konsumen

Penelitian Perhitungan Current Satisfaction Performance secara matematis adalah:

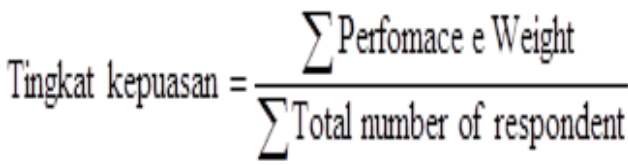

Performance Weight $=$ Number of Respondent $x$ Performance (Scale)

e. Menghitung Nilai Rasio Perbaikan (Improvement Ratio) untuk Setiap Atribut Kepentingan

Dalam bentuk matematis penentuan nilai Improvement Ratio adalah:

Improvemert Rasio $=\frac{\text { goal }}{\text { Current satisfaction performance }}$

f. Menghitung Bobot Perencanaan (Absolut)

Perhitungan bobot absolut dihitung dengan rumus:

Bobot absolut $=$ Tingkat kepentingan konsumen $\mathrm{x}$

rasio perbaikan $\mathrm{x}$ sales point

g. Nilai Bobot Perencanaan Relatif untuk Setiap Atribut

Besarnya nilai bobot perencanaan relative dihitung dengan rumus:

$$
\text { Bobot relatif }=\frac{\text { bobot absolut atribut kebutuhan }}{\text { total bobot absolut kebutuhan }} \times 100 \%
$$

h. Menetapkan Karakteristik Teknik terhadap Kebutuhan Konsumen

i. Menetapkan Tingkat Hubungan antara Kebutuhan Konsumen dengan Karakteristik Teknis

j. Menentukan Prioritas Desain Karakteristik Teknis Prioritas desain karakteristik teknis didapatkan berdasarkan bobot tingkat kepentingan absolut (TKA) atau bobot tingkat kepentingan relatif (TKR) dengan menggunakan rumus:

TKAi = hubungan h $_{\mathrm{ij}} \mathrm{x}$ bobot relatif

k. Menetapkan Hubungan antara Karakteristik Produk

I. Membuat home quality

\section{Hasil dan Pembahasan}

\section{Identifikasi Atribut Kebutuhan Konsumen}

Identifikasi kebutuhan konsumen dilakukan melalui penyebaran kue-sioner sehingga diperoleh 9 daftar kebutuhan konsumen terhadap perancangan alat press melinjo seperti pada atbel 1 dibawah ini.

Tabel 1. spesifikasi alat press melinjo berdasarkan keutuan konsumen

\begin{tabular}{cl}
\hline No & Atribut kebutuhan \\
\hline 1 & Bentuk gagang panjang \\
\hline 2 & Bentuk pegangan oval \\
\hline 3 & Bentuk Tempat tekan bulat \\
\hline 4 & Panjang gagang $40 \mathrm{~cm}$ \\
\hline 5 & Tinggi alat $50 \mathrm{~cm}$ \\
\hline 6 & Warna hitam \\
\hline 7 & Bahan Rangka besi \\
\hline 8 & Bahan pegangan karet \\
\hline 9 & Fungsi alat press biji melinjo \\
\hline
\end{tabular}




\section{Menyusun Matriks Perencanaan}

Penyusunan matriks perencanaan ini dilakukan untuk mendapatkan urutan atau prioritas atribut kebutuhan konsumen yang akan diusahakan dipenuhi oleh perancang alat press melinjo ini. Matriks perencanaan merupakan hasil kalkulasi dari beberapa jenis data dan oleh karena itu dalam menyusun matriks ini diperlukan beberapa tahapan, yaitu:

a. Penetapan Tingkat Kepentingan Konsumen (Importance to Customer) Penentuan tingkat kepentingan konsumen digunakan untuk mengetahui sejauh mana konsumen memberikan penilaian dari kebutuhan konsumen yang ada. Penilaian tingkat kepentingan terhadap atribut kebutuhan konsumen diperoleh berdasarkan nilai modus pada kuesioner tertutup.

b. Nilai modus yang menjadi tingkat kepentingan diperoleh berdasarkan frekuensi jawaban responden yang paling banyak pada setiap atribut. Tingkat kepentingan atribut kebutuhan konsumen secara lengkap dapat dilihat pada Tabel 2 berikut ini:

Tabel 2. Tingkat Kepentingan Atribut Kebutuhan

\begin{tabular}{|c|c|c|c|c|c|c|c|c|}
\hline \multicolumn{9}{|c|}{ Hasil kuesioner pengukuran } \\
\hline \multirow{2}{*}{ No } & \multirow{2}{*}{ Atribut Kebutuhan } & \multicolumn{5}{|c|}{ Skala } & \multirow{2}{*}{$\begin{array}{l}\text { Total } \\
\text { score }\end{array}$} & \multirow{2}{*}{$\underset{\text { kepuasan }}{\text { Tingkat }}$} \\
\hline & & 1 & 2 & 3 & 4 & 5 & & \\
\hline 1 & Bentuk gagang panjang & 0 & 4 & 23 & 3 & 0 & 89 & 0.85985 \\
\hline 2 & Bentuk pegangan oval & 1 & 8 & 18 & 3 & 0 & 83 & 0.87929 \\
\hline 3 & Bentuk Tempat tekan bulat & 5 & 18 & 5 & 2 & 0 & 64 & 0.92118 \\
\hline 4 & Panjang gagang $40 \mathrm{~cm}$ & 0 & $\frac{2}{2}$ & 8 & 17 & 3 & 111 & 135.618 \\
\hline 5 & Tinggi alat $50 \mathrm{~cm}$ & 2 & 1 & 4 & 17 & 6 & 114 & 156.089 \\
\hline 6 & Warna hitam & 4 & 2 & 9 & 5 & 10 & 105 & 210.245 \\
\hline 7 & Bahan Rangka besi & 10 & 15 & 5 & 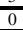 & $\frac{0}{0}$ & 55 & 0.87568 \\
\hline 8 & Bahan pegangan karet & 3 & 7 & 12 & 4 & 4 & 89 & 137.234 \\
\hline 9 & Fungsi alat press biji melinjo & 8 & 10 & 10 & 1 & 1 & 67 & 0.98208 \\
\hline
\end{tabular}

\section{Pengukuran Tingkat Kepuasan Konsumen}

Pengukuran tingkat kepuasan konsumen terhadap alat press melinjo saat ini dapat dicari dengan menggunakan rumus sebagai berikut:

Tingkat kepuasan $=\left(\sum\right.$ Perfomace e Weight $) /(\Sigma$ Total number of respondent)

Hasil perhitungan ini dapat dilihat pada Tabel 3 berikut ini:

Tabel 3. Tingkat Kepuasan atribut Kebutuhan Konsumen

\begin{tabular}{cccccccc}
\hline \multicolumn{7}{c}{ Hasil kuesioner pengukuran } \\
\hline \multirow{2}{*}{ No } & Atribut Kebutuhan & \multicolumn{7}{c}{ Skala } & $\begin{array}{c}\text { Tingkat } \\
\text { kepentin } \\
\text { gan }\end{array}$ \\
\cline { 3 - 8 } & Bentuk gagang panjang & 0 & 0 & 6 & 13 & 11 & 3 \\
\hline 1 & Bentuk pegangan oval & 0 & 0 & 23 & 7 & 0 & 3 \\
\hline 2 & Bentuk Tempat tekan bulat & 10 & 16 & 4 & 0 & 0 & 3 \\
\hline 3 & Panjang gagang $40 \mathrm{~cm}$ & 0 & 0 & 2 & 16 & 12 & 3 \\
\hline 4 & Tinggi alat $50 \mathrm{~cm}$ & 0 & 0 & 2 & 7 & 21 & 3 \\
\hline 5 & Warna hitam & 0 & 3 & 9 & 16 & 2 & 3 \\
\hline 6 & Bahan Rangka besi & 24 & 5 & 1 & 0 & 0 & 3 \\
\hline 7 & Bahan pegangan karet & 0 & 5 & 15 & 9 & 1 & 3 \\
\hline 8 & Fungsi alat press biji melinjo & 4 & 12 & 14 & 0 & 0 & 3 \\
\hline 9 & Jumlah & 38 & 41 & 76 & 68 & 47 & \\
\hline & & & & & & \\
\hline
\end{tabular}

\section{Menetapkan Hubungan antara Karakteristik Produk}

Menetapkan hubungan antara masing-masing karakteristik produk yang ada untuk menganalisa apakah antara karakteristik produk tersebut terdapat hubungan yang saling berkontradiksi (bernilai negatif). Menggambarkan tingkat hubungan antara masingmasing karakteristik produk yang ada digunakan simbol sebagai berikut:

- tingkat hubungan positif kuat

$\square$ : tingkat hubungan positif sedang

- $\quad$ : tidak ada hubungan

A : tingkat hubungan negatif kuat

$\triangle$ : tingkat hubungan negatif sedang

Tingkat hubungan antara masing-masing karakteristik produk dapat dilihat pada Gambar 1 berikut :

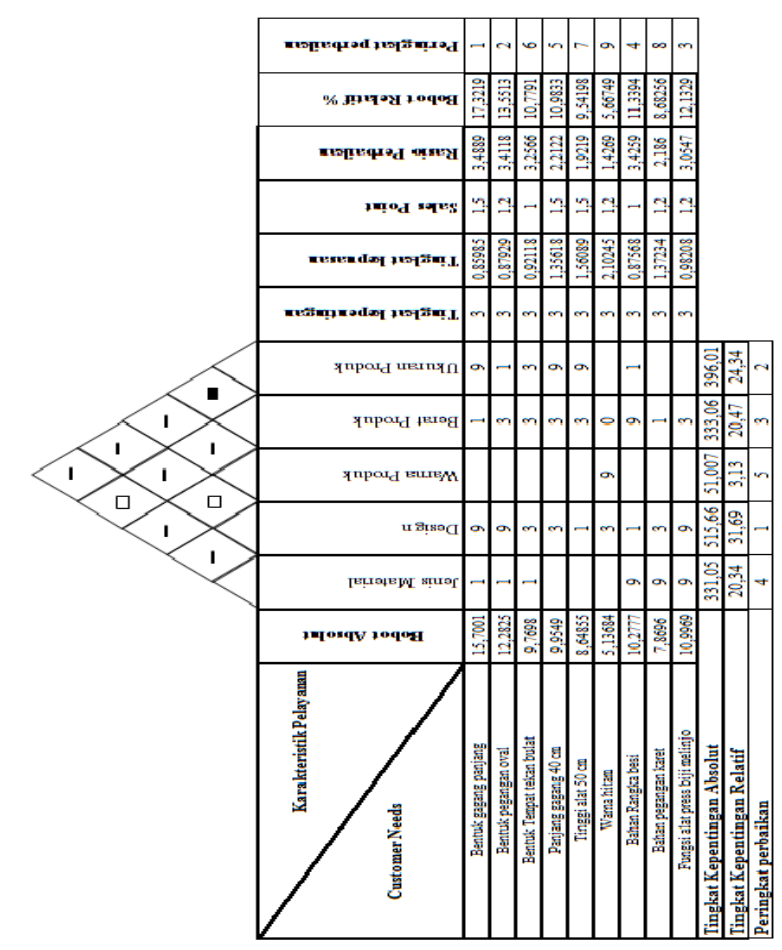

Gambar 1. Matriks Perencanaan

\section{Menentukan Prioritas Desain Karakteristik Teknis}

Prioritas desain karakteristik teknis didapatkan berdasarkan bobot tingkat kepentingan absolut (TKA) atau bobot tingkat kepentingan relatif (TKR) dengan menggunakan rumus:

\section{TKAi $=$ hubungan $_{\mathrm{ij}} \times$ bobot relatif}

Untuk lebih jelasnya, contoh perhitungan untuk penentuan TKA dari karakteristik teknis yaitu, agar dapat berguna dengan baik maka harus ada interaksi antar komponen, dapat dilihat pada Tabel 4. berikut 
Tabel 4. Tingkat prioritas desain teknik

\begin{tabular}{|c|l|c|c|c|}
\hline \multirow{2}{*}{ No. } & \multicolumn{1}{|c|}{$\begin{array}{c}\text { Atribut } \\
\text { kebutuhan }\end{array}$} & $\begin{array}{c}\text { Tingkat } \\
\text { Hubungan } \\
\text { Karakteristik } \\
\text { Teknis }\end{array}$ & $\begin{array}{c}\text { Bobot } \\
\text { Relatif }\end{array}$ & $\begin{array}{c}\text { Tingkat } \\
\text { Kepentingan } \\
\text { Absolut }\end{array}$ \\
\cline { 3 - 3 } & $\begin{array}{c}\text { Ukuran } \\
\text { Produk }\end{array}$ & & \\
\hline 1 & $\begin{array}{l}\text { Bentuk gagang } \\
\text { panjang }\end{array}$ & 9 & 17,32193 & 155,89737 \\
\hline 2 & $\begin{array}{l}\text { Bentuk } \\
\text { pegangan oval }\end{array}$ & 1 & 13,55131 & 13,55131 \\
\hline 3 & $\begin{array}{l}\text { Bentuk Tempat } \\
\text { tekan bulat }\end{array}$ & 3 & 10,77906 & 32,33718 \\
\hline 4 & $\begin{array}{l}\text { Panjang gagang } \\
40 \text { cm }\end{array}$ & 9 & 10,77906 & 97,01154 \\
\hline 5 & $\begin{array}{l}\text { Tinggi alat 50 } \\
\text { cm }\end{array}$ & 9 & 9,54198 & 85,87782 \\
\hline 6 & Warna hitam & 0 & 5,66749 & 0 \\
\hline 7 & $\begin{array}{l}\text { Bahan Rangka } \\
\text { besi }\end{array}$ & 1 & 11,33942 & 11,33942 \\
\hline 8 & $\begin{array}{l}\text { Bahan } \\
\text { pegangan karet }\end{array}$ & 0 & 8,68256 & 0 \\
\hline 9 & $\begin{array}{l}\text { Fungsi alat press } \\
\text { biji melinjo }\end{array}$ & 0 & 12,13294 & 0 \\
\hline & \multicolumn{2}{|l|}{ Jumlah } & & 396,01464 \\
\hline
\end{tabular}

\section{Design Produk Konseptual}

Berdasarkan hasil perancangan di atas, maka di buat desain konseptual produk seperti pada gambar 2 berikut.

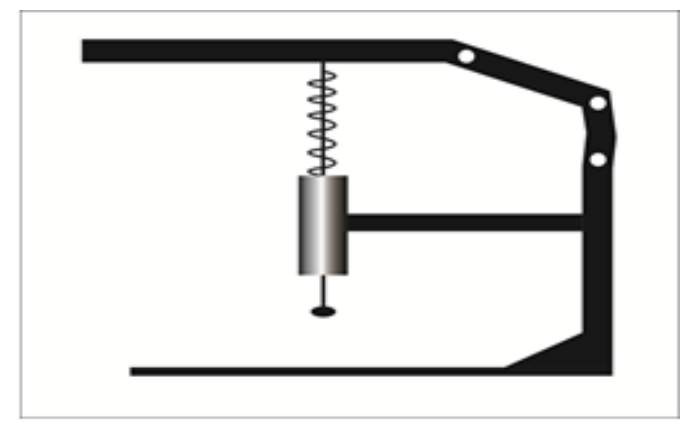

Gambar 2. Desain Konseptual produk alat prss melinjo

\section{Kesimpulan}

Berdasarkan hasil pengolahan data yang telah dilakukan dapat diambil beberapa kesimpulan sebagai berikut:

a. Konsumen menginginkan 9 atribut kebutuhan terhadap perancangan alat press biji melinjo sebagai berikut:

- Bentuk gagang panjang

- Bentuk pegangan oval

- Bentuk Tempat tekan bulat

- Panjang gagang $40 \mathrm{~cm}$

- Tinggi alat $50 \mathrm{~cm}$

- Warna hitam

- Bahan rangka besi

- Bahan pegangan karet

- Fungsi alat press biji melinjo b. Tingkat kepuasan atribut kebutuhan konsumen terhadap alat press biji melinjo saat ini yang paling besar adalah hasil warna hitam sebesar 210.245.

\section{Daftar Pustaka}

[1]Akao, Yoji. (1990). QFD Integrating costumer requiremens into product design. USA: Productivity Press.

[2 ] Haryoto. 1998. Membuat Emping Melinjo. Kanisius. Yogyakarta.

[3 ] Karuniawati, Fardiana. 2009. Desain layanan IPTV dengan menggunakan metode Quality Function Deployment (QFD) untuk wilayah Bandung.

[4] Lou Cohen. 1995. Quality Function Deployment. Prentice Hall PTR

[5 ] Noegraha, A. 2010. Melinjo Sebagai Salah Satu Usaha Peningkatan Nilai Tambah Sumber daya Lokal Berbasis Agribisnis

[6] Rahmatika, N.H. 2008. Penerapan quality function deployment (QFD) untuk mengetahui tingkat kepuasaan konsumen produk biskuit di PT. Arnott's Indonesia. Skripsi. Fakultas Teknologi Pertanian, Institut Pertanian Bogor, Bogor 